\title{
EFFECTS OF MAGNETIZED BRACKISH WATER ON SEED GERMINATION, SEEDLING GROWTH, PHOTOSYNTHESIS AND DRY MATTER DISTRIBUTION OF COTTON (GOSSYPIUM HIRSUTUM L.)
}

\author{
ZHANG, J. H. - WANG, Q. J. ${ }^{*}$ - WEI, K. - SUN, Y. - MU, W. Y. \\ State Key Laboratory of Eco-hydraulics in Northwest Arid Region of China, Xi'an University of \\ Technology, Xi'an 710048, China \\ ${ }^{*}$ Corresponding author \\ e-mail:wquanjiu@163.com
}

(Received 27 $7^{\text {th }}$ Sep 2020; accepted $18^{\text {th }}$ Dec 2020)

\begin{abstract}
Magnetized water is widely used in agricultural irrigation as a new type of biomagnetic technology in China. In order to understand the biological effects of different strength magnetized brackish water, seed germination and potted experiments were carried out to study its effects of magnetized brackish water with different magnetic intensities $(0,100 \mathrm{mT}, 300 \mathrm{mT}, 500 \mathrm{mT})$ on seed germination and seedling growth. The germination vigor indexes of cotton cultivated with magnetized brackish water significantly increased, and the germination potential and vigor index increased by $39.4-60.6 \%$ and $129.1-246.3 \%$, respectively. The emergence rate of cotton under magnetized brackish water irrigation was faster and higher, with an increase range of 7.5-41.9\%. The net photosynthetic rate $\left(P_{n}\right)$ and instantaneous water use efficiency $(i W U E)$ of cotton under magnetized brackish water irrigation increased significantly, whereas the stomatal limit value $\left(L_{s}\right)$ decreased. The total biomasses of cotton under magnetized brackish water irrigation were significantly increased, but the stem weight ratio and leaf weight ratio had no significant changes. Hence, magnetized brackish water can promote the utilization of water and light, and cotton irrigated with $300 \mathrm{mT}$ magnetic field intensity is most conducive to the growth of cotton seedlings.

Keywords: magnetic water treatment, biological effect, early growth of cotton, water use efficiency, efficiency of utilization of light
\end{abstract}

\section{Introduction}

Fresh water resources are an important material basis for human survival and development, as well as a basic condition for agricultural production (Shrestha et al., 2017). With the rapid development of social economy and the continuous increase of population, the lack of fresh water resources has become a worldwide problem, posing a serious threat to agricultural production and the ecological environment (Wang et al., 2020). Therefore, how to solve the problem of fresh water resource crisis has become a very urgent task (Murshed and Kaluarachchi, 2018).

In order to alleviate the contradiction between the supply and demand of fresh water resources, in recent years, countries in the world have taken the development and utilization of low-quality water as an important means (Zhou et al., 2019), and brackish water is widely distributed and has large reserves, so it has become the main water source for development and utilization (Faulkner et al., 2019). The scientific and reasonable development and utilization of brackish water resources play an extremely important role in alleviating the shortage of fresh water resources, expanding agricultural water sources, fighting drought, and increasing production (Honarparvar et al., 2019). However, brackish water irrigation can easily cause secondary salinization of the soil, causing the soil salinity of the plough layer or the concentration of the soil solution to exceed the salinity tolerance of the crop, 
thereby affecting crop growth and yield (Huang et al., 2019). Therefore, the treatment and scientific use of brackish water, the prevention and control of soil secondary salinization, and the maintenance of sustainable development of land resources have become the core issues in the development and utilization of brackish water (Zhong et al., 2018; Mollahosseini and Abdelrasoul, 2019).

With the development of magnetized water research, this technology has also achieved good results in agricultural irrigation (Aliverdi et al., 2015; Al-Ogaidi et al., 2017). Some researchers conducted irrigation experiments with magnetized saline water (brackish water), and the results showed that magnetization treatment can reduce the harm of brackish water (brackish water), promote crop growth, and increase crop yield (Alavi et al., 2020; Liu et al., 2020). Surendran et al. (2016) indicated that under field conditions, the yield of eggplant under magnetized water irrigation increased by $17.0 \%$. Hozayn et al. (2019) showed that the grain yield, straw yield, and biological yield of magnetized brackish water increased by $19.24 \%, 33.97 \%$, and $26.99 \%$, respectively. Moreover, studies on the early growth of crops with magnetized water irrigation found that magnetized water irrigation significantly improved the germination rate, germination index, activity index, salt tolerance index, and other physiological factors of corn (Zea mays L.) seeds, and promoted the growth of seedlings under saline conditions (Aghamir et al., 2015). Sayed and Sayed (2014) indicated that magnetized water irrigation had a significant positive effect on the growth parameters (plant height, leaf area, leaf, stem, root brackish weight, and dry weight) of broad bean (Vicia Faba L.) seedlings. Studies on the utilization of light energy of crops by magnetized water irrigation showed that the net photosynthetic rate, stomatal conductance, intercellular $\mathrm{CO}_{2}$ concentration, and water use efficiency of Populus $\times$ euramericana 'Neva' in magnetized brackish water irrigation were all increased, while transpiration rate and stomatal limit value were all decreased compared with that of unmagnetized water (Liu et al., 2019a). Alfaidi et al. (2017) found that the contents of chlorophyll a, b, carotenoids, total pigment, soluble protein, and total protein in guinea grass (panicum maximum) leaves were significantly increased after irrigating with magnetized water. More importantly, the growth promoting effect of magnetized water is related to the magnetic field strength and irrigation water quality. Massah et al. (2019) indicated that the intensity of magnetic field and the type of treated water had a significant effect on the germination and growth characteristics of wheat seeds. The germination rate of seeds treated with $400 \mathrm{mT}$ of distilled water was the highest $(53.3 \%)$, the brackish weight of seedlings treated with $600 \mathrm{mT}$ of distilled water was the highest, and the root length of wheat seeds treated with $400 \mathrm{mT}$ of groundwater was the largest $(155.3 \mathrm{~mm})$.

To sum up, remarkable achievements have been made in irrigating wheat, corn, broad bean, and eggplant with magnetized water, but the research on irrigating cotton with magnetized water is insufficient. At the same time, there are few studies on the magnetization of brackish water. Therefore, it is necessary to explore the effects of magnetized brackish water with different magnetic fields on the growth of crops, especially on the fragile and sensitive seedling stage of crop growth. Therefore, in this paper, cotton was used as experimental material, through the analysis of cotton seed germination, seedling emergence, seedling growth, photosynthetic characteristics parameters and biomass distribution pattern, the effects of magnetized brackish water with different magnetization intensities $(0,100 \mathrm{mT}, 300 \mathrm{mT}, 500 \mathrm{mT})$ on cotton seedling growth and photosynthetic characteristics were discussed, and the suitable cotton seed germination and seedling were determined. The results can provide a theoretical basis and technical support for the efficient utilization of brackish water resources in arid and semiarid areas. 


\section{Materials and methods}

\section{Experimental site description}

The experimental site is located in Bazhou Irrigation Experimental Station of Xinjiang Tarim River Basin Authority, which is located in the Bayingoleng Mongolian Autonomous Prefecture of Xinjiang in the middle of Eurasia continent (Liang et al., 2020). It is a typical continental arid climate type and an important cotton (Gossypium hirsutum L.) planting area in Northwest China (Chen et al., 2020). The experimental station is $41^{\circ} 35^{\prime} \mathrm{N}$ and $86^{\circ} 10^{\prime} \mathrm{E}$, with an elevation of $901 \mathrm{~m}$ (Yang et al., 2016). The annual average precipitation is only $58 \mathrm{~mm}$, and the maximum potential evaporation is $2788.2 \mathrm{~mm}$ (Tian et al., 2017). The annual sunshine in this region is $3036.2 \mathrm{~h}$, the frostfree period is $144-241 \mathrm{~d}$, the average wind speed is $2.4 \mathrm{~m} \cdot \mathrm{s}^{-1}$, the highest wind speed is $22 \mathrm{~m} \cdot \mathrm{s}^{-1}$ (Li et al., 2019). The annual average maximum, minimum and average temperatures are $11.5,42.2$, and $30.9{ }^{\circ} \mathrm{C}$, respectively (Tan et al., 2017). The brackish water used for irrigation in the test station is groundwater with an average salinity of $5.49 \mathrm{~g} \cdot \mathrm{L}^{-1}$ and $\mathrm{pH}$ of 7.84 .

\section{Magnetizer and magnetized water device}

Three external CHQ permanent magnet magnetizers (Shanghai Juncai Magnetic Materials Co., LTD., China) with magnetic field strength of $100 \mathrm{mT}, 300 \mathrm{mT}$, and $500 \mathrm{mT}$ were used in the test, and they were made of sintered Rufe-B. The effective magnetic field area was $8 \mathrm{~cm} \times 10 \mathrm{~cm}$ and the magnetic field intensities are calibrated with the 5180-Gaussian Meter (F.W. BELL Co., USA). The magnetized water device is composed of a water box, peristaltic pump, magnetizer, water pipeline, and valves. The water pipeline is a PVC pipe with a $2.5 \mathrm{~cm}$ diameter (cross-sectional area of $4.91 \mathrm{~cm}^{2}$ ), and the length of the pipeline passing through the magnetic field (effective magnetic distance) is $10 \mathrm{~cm}$. As shown in Fig. 1, 100 L of irrigation water was placed in the water box, and a pipeline was opened one at a time through a valve control. The peristaltic pump was used to circulate the water in a closed pipeline. A section of the circulating pipeline was placed between the two poles of the magnetizer, and the magnetic induction line was cut perpendicular to the magnetic field. The flow rate was adjusted to $0.5 \mathrm{~m} \cdot \mathrm{s}^{-1}$ by the peristaltic pump, and the flow was cyclically magnetized by the magnetic field. The magnetization time was $30 \mathrm{~min}$.

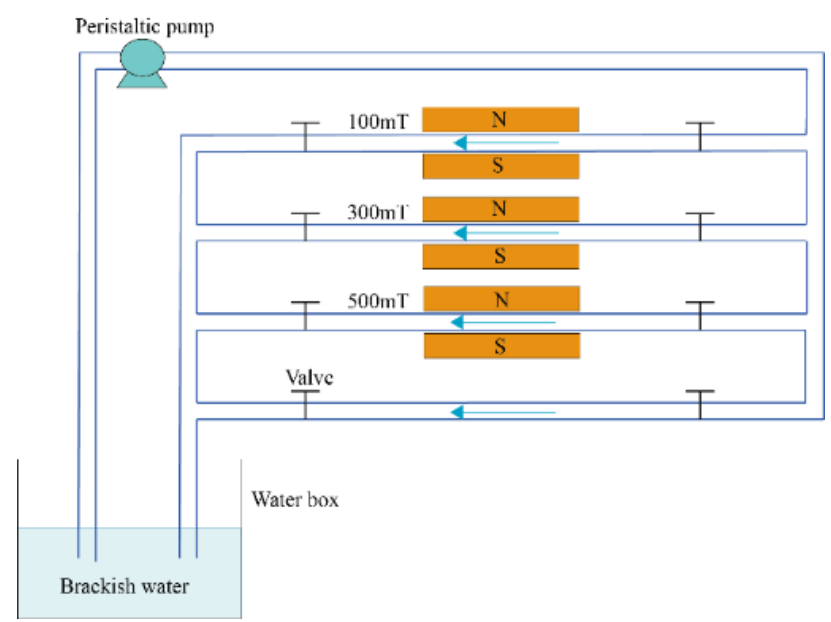

Figure 1. Schematic diagram of magnetized brackish water device 


\section{Experimental design and process}

The above magnetized water device was used to magnetize brackish water with different magnetic field intensities. Unmagnetized brackish water was used as a control, and a total of 4 treatments were formed: unmagnetized brackish water (BM0), $100 \mathrm{mT}$ magnetized brackish water (BM1), $300 \mathrm{mT}$ magnetized brackish water (BM3) and $500 \mathrm{mT}$ magnetized brackish water (FM5). A series of experiments including cotton seed germination and potted experiments in a cotton field were carried out with the four kinds of treated water to analyze the influence of magnetized brackish water with different magnetic field intensities on cotton seed germination and seedling growth, in 2018.

\section{Experiment 1-seed germination test}

Seed germination tests were performed as described in a previous study with three repetitions (Fu et al., 2010). 50 cotton seeds of the same size and full grain were selected and arranged evenly in a petri dish with tweezers. The petri dish was then marked and covered with a layer of filter paper. $20 \mathrm{~mL}$ of treated water was added to the corresponding culture dish and the seeds were covered with a layer of fine paper. After the seeds had reached the constant weight, the excess water was drained, and then the seeds were placed in the culture dish in the incubator at $28 \pm 1{ }^{\circ} \mathrm{C}$, with a light intensity of $800 \mathrm{Lx}$. The number of germinations was recorded every day, and the corresponding treatment water was added in time to maintain the moisture content of the filter paper. The radicle length of cotton seeds was measured on the eighth day. The germination condition was evaluated by calculating germination potential $(G P)$, germination rate $(G R)$, germination index $(G I)$, and vigor index $(V I)$. The Calculation methods for each index are as Eq.1-Eq.4 (Mosse et al., 2013).

$$
\begin{gathered}
G P=\frac{N_{4}}{N_{T}} \times 100 \% \\
G R=\frac{N_{8}}{N_{T}} \times 100 \% \\
G I=\sum \frac{G_{t}}{D t} \\
V I=G I \times L
\end{gathered}
$$

where, $N_{4}$ and $N_{8}$ are the number of seeds germinated in 4 days and 8 days, respectively. $N_{T}$ is the total number of seeds, $G_{t}$ is the number of seeds germinated at day $\mathrm{t}(D t)$, and $L$ is the average radicle length of seed on the eighth day.

\section{Experiment 2-potted experiments in a cotton field}

To simulate the growth environment of field cotton, all the potted plants were buried in the cotton field, randomly divided, and repeated three times. Saline alkali soil from 0-20 cm depth from the surface of the cotton field was used in the experiment. According 
to the soil texture classification of the U.S. Department of Agriculture, the soil was sandy loam $\left(64.27 \%\right.$ sand, $32.83 \%$ silt, $2.9 \%$ clay), and soil bulk density was $1.63 \mathrm{~g} \cdot \mathrm{cm}^{-3}$, saturated water content was $0.395 \mathrm{~cm}^{3} \cdot \mathrm{cm}^{-3}$, the wilting coefficient was $0.050 \mathrm{~cm}^{3} \cdot \mathrm{cm}^{-3}$, field capacity was $0.196 \mathrm{~cm}^{3} \cdot \mathrm{cm}^{-3}$, and soil extract conductivity (ECe) was $5.47 \mathrm{ds} \cdot \mathrm{m}^{-1}$. The inner diameter and height of the plastic basin used in the test were $30 \mathrm{~cm}$ and $20 \mathrm{~cm}$ respectively, and 8 air holes with a diameter of $10 \mathrm{~mm}$ were set at the bottom of the basin. After the fertilizer and soil were mixed evenly, each barrel was uniformly loaded with $20 \mathrm{~kg}$ of soil sample. The fertilizer added per barrel was as follows: carbamide (N 45.4\%) $6.8 \mathrm{~g}$, compound fertilizer (N 12\%, P 18\%, K 15\%) $6.4 \mathrm{~g}$, organic fertilizer (organic matter $>35 \%) 24 \mathrm{~g}$. The amount of water applied before sowing was calculated according to the amount of spring irrigation in the field $(100 \mathrm{~mm})$. After sowing, the cotton at the seedling stage was no longer irrigated as in the field. Each pot was seeded with 20 cotton seeds, with a sowing depth of $2-3 \mathrm{~cm}$. As in the field, the soil surface was covered with plastic film mulch after sowing.

Fourteen days after sowing, the rate of emergence was measured and only 4 cotton plants were kept in each pot, with the remaining seedlings being removed. The length of cotton seedlings was then measured, the dust on the surface was removed, and the brackish weight of the seedling was measured after washing and drying. Then, the seedlings were placed in an oven at $105^{\circ} \mathrm{C}$ for $1 \mathrm{~h}$ and dried at $75^{\circ} \mathrm{C}$, and the dry weight of the seedling was measured after they had cooled down. Plant height, stem diameter at cotyledon node, number of leaves per plant, and area of single leaf of potted cotton were measured. The stem diameter was measured with an electronic Vernier caliper with an accuracy of $0.01 \mathrm{~mm}$. The number of leaves was counted manually. Plant height, leaf width, and vein length were measured with measuring tape with an accuracy of $1 \mathrm{~mm}$. The area of a single leaf was calculated with the formula length $\times$ width $\times 0.84$ (Tan et al., 2017). The growth indexes of potted cotton seedlings were measured every 10 days after final singling. Thirty days after final singling, the net photosynthetic rate $\left(P_{n}\right)$, stomatal conductance $\left(G_{s}\right)$, intercellular $\mathrm{CO}_{2}$ concentration $\left(C_{i}\right)$, and transpiration rate $\left(T_{r}\right)$ of the main functional leaves (from the top to the bottom of the fourth leaf) of cotton seedlings were measured using LC Pro SD full-automatic portable photosynthetic instrument (UK ADC) equipped with an LED artificial light source. Then, the stomatal limit $L s=1-C_{i} / C_{a}$ ( $C_{a}$ is atmospheric $\mathrm{CO}_{2}$ concentration) and instantaneous water use efficiency $i W U E=P_{n} / T_{r}$ were calculated (Liu et al., 2017). When determining the photosynthesis parameters of cotton seedlings, according to the meteorological environment conditions during 10:00-12:00 am in the cotton field, the light intensity was set as $1100 \mu \mathrm{mol} \cdot \mathrm{m}^{-2} \cdot \mathrm{s}^{-1}$, the concentration of $\mathrm{CO}_{2}$ was $360 \mu \mathrm{mol} \cdot \mathrm{mol}^{-1}$, and the temperature was $30^{\circ} \mathrm{C}$. Forty days after final singling, the cotton seedlings were removed slowly. The cotton branches were then cut with fruit scissors, the dust was removed from the surface, the cotton branches were washed and dried, and the dry weight of each part was weighed.

\section{Data processing and analysis}

The data were recorded in Excel 2016 and analyzed using SPSS 22.0 software (IBM Corp. USA). The least significant difference (LSD) method $(P<0.05)$ was used for comparison of multiple values. 


\section{Results and Discussion}

\section{Analysis of germination characteristics of cotton seeds}

Seed germination refers to the process of resuming material synthesis and metabolism after the vigorous seed swells, prompting the radicle to expose the seed coat (Hadi et al., 2018; Yue et al., 2019). Seed germination is extremely susceptible to external environmental factors such as light, temperature, moisture, and salinity (Castillo et al., 2017; Luo et al., 2019), and magnetized water treatment also has an important impact on seed germination (Sappington and Rifai, 2018). Germination characteristics of cotton cultivated with different magnetized brackish water were analyzed by comparing Germination potential $(G P)$, germination rate $(G R)$, germination index $(G I)$, and vigor index (VI) (Table 1). Compared with unmagnetized brackish water, the GP, GR, GI, and $V I$ of magnetized brackish water were significantly increased $(P<0.05)$, with the ranges of 39.4-60.6\%, 23.5-49.0\%, 30.0-58.5\%, and 129.1-246.3\%, respectively, and the VI was the most sensitive to magnetized brackish water treatment. The results were consistent with the research results of Massah et al. (2019), who applied magnetized brackish water to promote the germination of wheat seeds. The increase range of germination potential was greater than that of germination rate, while the increase range of vigor index was greater than that of germination index, indicating that brackish water magnetization could significantly improve the seed vigor of cotton and enhance the germination potential of cotton. This may be due to magnetized brackish water has a function similar to plant growth hormone, which can stimulate the activity of the seed enzyme system or accelerate the synthesis of related enzymes, enhance the enzymatic reactions in seeds, and thus improve the seed activity (Boe and Salunkhe, 1963). Compared with the germination indexes of cotton seeds cultivated by brackish water with different magnetized intensities, it could be found that the germination indexes of cotton seeds cultivated by BM3 improved the most, the $V I$ of cotton seeds treated with BM5 was significantly higher than that of BM1, while the $G P, G R, G I$ had no significant difference $(P>0.05)$.

Table 1. Germination indexes of cotton seeds under different strength of magnetized brackish water $(n=3)$

\begin{tabular}{c|c|c|c|c}
\hline Treatment & $\begin{array}{c}\text { Germination potential }(\boldsymbol{G P}) \\
(\boldsymbol{\%})\end{array}$ & Germination rate $(\boldsymbol{G R})(\boldsymbol{\%})$ & $\begin{array}{c}\text { Germination index } \\
(\boldsymbol{G I})\end{array}$ & $\begin{array}{c}\text { Vigor index } \\
(\boldsymbol{V} \boldsymbol{)})\end{array}$ \\
\hline BM0 & $22.0 \pm 2.0 \mathrm{c}$ & $34.0 \pm 2.0 \mathrm{c}$ & $8.0 \pm 0.3 \mathrm{c}$ & $7.0 \pm 1.4 \mathrm{~d}$ \\
BM1 & $30.7 \pm 2.3 \mathrm{~b}$ & $42.0 \pm 2.0 \mathrm{~b}$ & $10.5 \pm 0.4 \mathrm{~b}$ & $16.0 \pm 1.2 \mathrm{c}$ \\
BM3 & $35.3 \pm 1.2 \mathrm{a}$ & $50.7 \pm 4.2 \mathrm{a}$ & $12.8 \pm 0.5 \mathrm{a}$ & $24.2 \pm 1.7 \mathrm{a}$ \\
BM5 & $32.0 \pm 2.0 \mathrm{ab}$ & $45.3 \pm 1.2 \mathrm{~b}$ & $11.2 \pm 0.2 \mathrm{~b}$ & $19.0 \pm 0.8 \mathrm{~b}$ \\
\hline
\end{tabular}

Different letters within a column indicate significant differences among all treatments at $P<0.05$

\section{Effect of magnetized brackish water irrigation on the emergence rate of cotton}

High seedling emergence rate and seedling uniformity are the guarantees for high and stable yield (Wang et al., 2016; Liang et al., 2018). The emergence of cotton seeds started 3 days after sowing (Fig. 2). With the increase of emergence time, the emergence rate of cotton gradually increased and tended to be stable. The emergence rate of cotton under magnetized brackish water irrigation was faster and higher. The emergence rate and full seedling formation of cotton irrigated with BM0 was $58.9 \%$ and $9 \mathrm{~d}$, respectively, while the emergence rates of cotton irrigated with BM1, BM3 and BM5 were 63.3\%, 83.6\%, and $70.0 \%$ respectively, and the full seedling formations were $9 \mathrm{~d}, 8 \mathrm{~d}$, and $9 \mathrm{~d}$, 
respectively. Compared with $\mathrm{BM} 0$, the emergence rate of cotton irrigated with magnetized brackish water increased by $7.5-41.9 \%$, and the full seedling formation of cotton irrigated with BM3 was advanced by $1 \mathrm{~d}$. Similarly, Moussa (2011) applied magnetized brackish water irrigation to improve the emergence rate of snow peas and chickpeas. The effect of BM3 on cotton seedling emergence was the best, while the effect of BM5 on cotton seedling emergence was better than that of BM1.

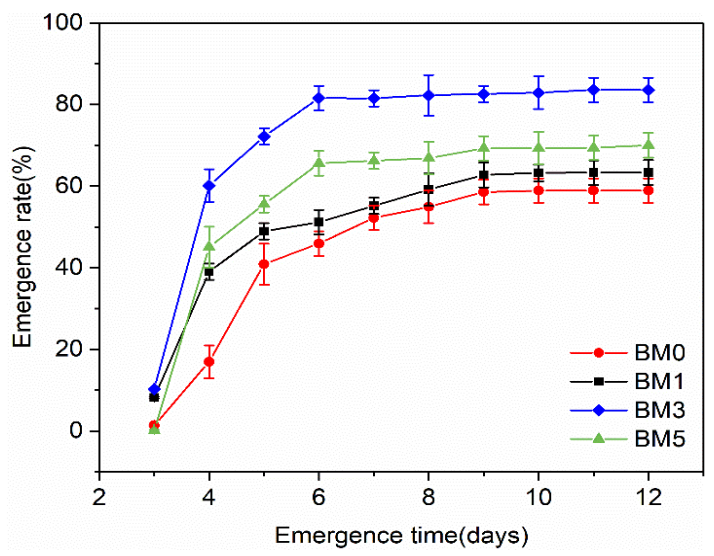

Figure 2. The effect of different strength of magnetized brackish water irrigation on the emergence rate of cotton $(n=3)$. The error bars represent standard deviations

The vitality of cotton seedlings was analyzed by seedling height, root length, fresh weight, dry weight, and seedling water content (Velmala et al., 2018). The cotton seeds were removed 14 days after sowing and seedling activity indexes were measured and analyzed (Table 2). Compared to unmagnetized brackish water, the activity of cotton seedling under magnetized brackish water irrigation was significantly increased ( $\mathrm{P}<0.05)$, and the seedling height, root length, fresh weight, dry weight, and water content increased by 41.6-55.2\%, 29.5-54.5\%, 55.1-76.4\%, 23.1-35.8\%, and 5.8-6.3\%, respectively. Among them, seeding root length and seedling fresh weight increased significantly, while seedling water content increased less than $8 \%$, indicating that magnetized brackish water mainly improves seedling vitality and ensures the seedling healthy by promoting seeding root growth and increasing seedling fresh weight (Surendran et al., 2016). The effects of magnetized brackish water irrigation with different magnetic field strengths on the activity of cotton seedlings were significantly different $(P<0.05)$. FM3 had the best promoting effect on seedling vigor, while the seedling water content had no significant difference $(P>0.05)$. The seeding height, fresh weight, and dry weight of cotton irrigated with FM5 were 1.7-5.6\% higher than those with FM1, but the difference was not significant.

Table 2. Characteristics of seedling activity of cotton under magnetized and unmagnetized brackish water $(n=3)$

\begin{tabular}{c|c|c|c|c|c}
\hline Treatment & $\begin{array}{c}\text { Seedling height } \\
(\mathbf{c m})\end{array}$ & $\begin{array}{c}\text { Seedling root } \\
\text { length }(\mathbf{c m})\end{array}$ & Fresh weight $(\mathbf{g})$ & Dry weight $(\mathbf{g})$ & $\begin{array}{c}\text { Seedling water } \\
\text { content }(\boldsymbol{\%})\end{array}$ \\
\hline BM0 & $4.2 \pm 0.1 \mathrm{c}$ & $2.9 \pm 0.2 \mathrm{c}$ & $2.64 \pm 0.07 \mathrm{c}$ & $0.58 \pm 0.02 \mathrm{c}$ & $78.13 \pm 0.09 \mathrm{c}$ \\
BM1 & $5.9 \pm 0.3 \mathrm{~b}$ & $4.0 \pm 0.3 \mathrm{~b}$ & $4.09 \pm 0.12 \mathrm{~b}$ & $0.71 \pm 0.01 \mathrm{~b}$ & $82.63 \pm 0.59 \mathrm{a}$ \\
BM3 & $6.5 \pm 0.1 \mathrm{a}$ & $4.5 \pm 0.4 \mathrm{a}$ & $4.65 \pm 0.42 \mathrm{a}$ & $0.78 \pm 0.03 \mathrm{a}$ & $83.03 \pm 2.09 \mathrm{a}$ \\
BM5 & $6.0 \pm 0.2 \mathrm{~b}$ & $3.8 \pm 0.1 \mathrm{~b}$ & $4.32 \pm 0.27 \mathrm{ab}$ & $0.73 \pm 0.01 \mathrm{~b}$ & $82.97 \pm 1.3 \mathrm{a}$ \\
\hline
\end{tabular}

Different letters within a column indicate significant differences among all treatments at $P<0.05$ 


\section{Effect of magnetized brackish water irrigation on growth characteristics of cotton}

Crops adapt to environmental stress by changing their growth rate and morphology (Ramírez-Pérez et al., 2018; Dziedzic et al., 2019). The growth indexes of cotton all increased with the increase of growth time, and there was a small difference between the growth indexes of cotton irrigated with magnetized and unmagnetized brackish water $10 \mathrm{~d}$ after final singling. With the increase of growth time, the difference between the growth indexes of cotton irrigated with magnetized and unmagnetized brackish water gradually increased (Fig. 3). In the same growth period, the plant height, stem diameter, leaf number, and single leaf area of magnetized brackish water irrigation were larger than those of unmagnetized brackish water. After 10-40 d of final singling, the average growth rate of BM0 irrigated cotton plant height was $0.31 \mathrm{~cm} \cdot \mathrm{d}^{-1}$, and the peak growth rate of plant height was 30-40 d after final singling. While the average growth rates of cotton plant height under BM1, BM3 and BM5 were $0.44,0.60$, and $0.53 \mathrm{~cm} \cdot \mathrm{d}^{-1}$, respectively, and all the peaks of plant height growth rate were 30-40 d after final singling. Compared to FM0, the plant height of cotton irrigated with BM1, BM3, and BM5 increased by $52.0 \%, 100.7 \%$, and $79.1 \%$, respectively, $40 \mathrm{~d}$ after final singling (Fig. 3A), which was consistent with the research results of (Yusuf and Ogunlela, 2015). After 10-40 d of final singling, the average growth rate of BM0 irrigated cotton stem diameter was $0.07 \mathrm{~mm} \cdot \mathrm{d}^{-1}$, and the peaks growth rate of stem diameter were 10-20 d after final singling. While the average growth rates of cotton stem diameter under BM1, BM3, and BM5 were 0.11, 0.14 , and $0.12 \mathrm{~mm} \cdot \mathrm{d}^{-1}$, respectively, and all the peaks of stem diameter growth rate were 30-40 d after final singling. Compared to BM0, the stem diameter of cotton irrigated with BM1, BM3, and BM5 increased by $57.9 \%, 108.1 \%$ and $76.6 \%$, respectively, $40 \mathrm{~d}$ after final singling (Fig. 3B). Compared to BM0, the number of cotton leaves irrigated with BM1, BM3 and BM5 increased by 55.6\%, 100.0\%, and 77.8\% (Fig. 3C), respectively, while the single leaf area increased by $38.0 \%, 83.2 \%$, and $59.4 \%$ (Fig. 3D), respectively, $40 \mathrm{~d}$ after final singling. Compared with different intensities of magnetized brackish water, BM3 had the greatest promoting effect on cotton growth, while BM5 had a better promoting effect on cotton growth than BM1.

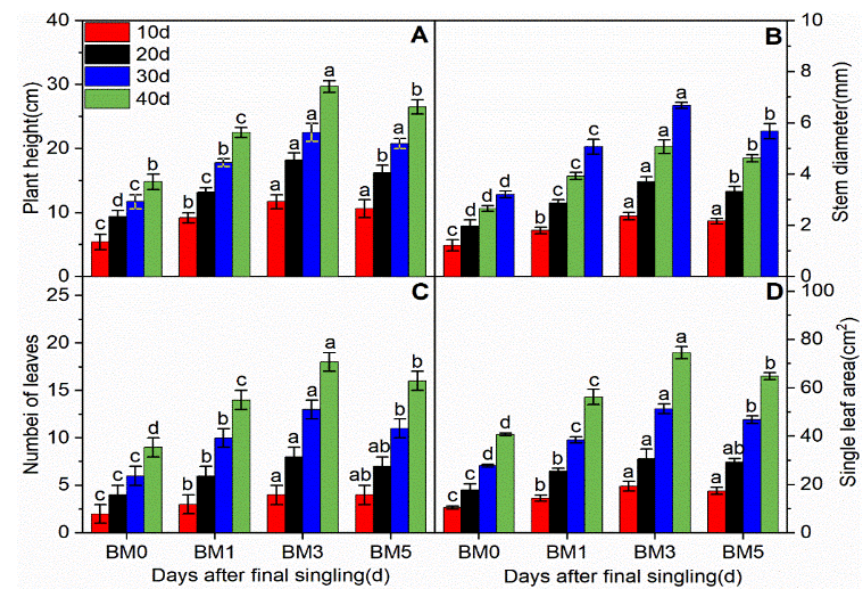

Figure 3. Effect of magnetized and unmagnetized brackish water irrigation on cotton morphological indexes. 10d, 20d, 30d and 40d represent 10d, 20d, 30dand 40d after final singling, respectively. BMO represents unmagnetized brackish water, while BM1, BM3 and BM5 represent brackish water treated with magnetic field intensities of $100 \mathrm{mT}, 300 \mathrm{mT}$ and $500 \mathrm{mT}$, respectively $(n=3)$. The error bars represent standard deviations. Different letters within a column indicate significant differences among all treatments at $P<0.05$ 


\section{Effect of magnetized brackish water irrigation on photosynthetic characteristic parameters of cotton}

Photosynthesis is a key process that promotes the growth and development of crops (Kulmala et al., 2019), and magnetized brackish water irrigation plays a role in crop growth by affecting the photosynthesis process (Liu et al., 2020). The characteristic photosynthetic parameters of magnetized and unmagnetized brackish water irrigated cotton are shown in Fig. 4. The net photosynthetic rate $\left(P_{n}\right)$ of cotton irrigated with BM0 was $12.60 \mu \mathrm{mol} \cdot \mathrm{m}^{-2} \cdot \mathrm{s}^{-1}$, and the $P_{n}$ of cotton irrigated with BM3 and BM5 increased by $45.2 \%$ and $26.4 \%$, respectively, while there was no significant difference between BM1 and BM0 (Fig. 4A). The transpiration rate $\left(T_{r}\right)$ of cotton irrigated with BM0 was $4.86 \mathrm{mmol} \cdot \mathrm{m}^{-2} \cdot \mathrm{s}^{-1}$, and the $T_{r}$ of cotton irrigated with BM1 was $2.9 \%$ bigger than that of BM0, while the $T_{r}$ of cotton irrigated with BM3 and BM5 was increased by $2.1-14.1 \%$, but all the difference was not significant $(F i g .4 B)$. The stomatal conductance $\left(G_{s}\right)$ of cotton irrigated with BM0 was $0.180 \mathrm{mmol} \cdot \mathrm{m}^{-2} \cdot \mathrm{s}^{-1}$, and the $G_{s}$ of cotton irrigated with BM3 and BM5 increased by $46.7 \%$ and $42.2 \%$, respectively, while there was no significant difference between BM1 and BM0 (Fig. 4C). The intercellular $\mathrm{CO}_{2}$ concentration $\left(C_{i}\right)$ of cotton irrigated with BM0 was $126.8 \mu \mathrm{mol} \cdot \mathrm{mol}^{-1}$, and the $C_{i}$ of cotton irrigated with BM1, BM3 and BM5 increased by $22.4 \%, 54.9 \%$, and $41.0 \%$, respectively (Fig. 4D). Compared with $\mathrm{BM} 0$, the instantaneous water use efficiency ( $i W U E$ ) of cotton irrigated with BM3 and BM5 increased by $25.1 \%$ and $23.8 \%$ (Fig. 4E), while the stomatal limit $\left(L_{s}\right)$ decreased by $25.0 \%$ and $21.9 \%$ (Fig. $4 F$ ). The $L_{s}$ of cotton irrigated with BM1 decreased by $18.8 \%$, while $i W U E$ did not change significantly. This indicated that magnetized water treatment could effectively improve the stomatal conductance of cotton seedlings, reduce stomatal limitation and improve the supply of $\mathrm{CO}_{2}$, thus improving the photosynthetic carbon assimilation capacity and enhancing the utilization efficiency of light energy and water. This is consistent with the research results of Hasan et al. (2017) and Qiu et al. (2011). Comparing the effects of magnetized brackish water with different intensities on the photosynthetic characteristic parameters of cotton, it could be found that the Ls of cotton irrigated with BM3 was the lowest, while the $P_{n}$ and $i W U E$ were the largest, and BM5 was better than BM1. In this study, magnetized water irrigation maintained relatively high $P_{n}, G_{s}, C_{i}, T_{r}, i W U E$, and chlorophyll SPAD values and low $L_{s}$ values (Fig. 4A-F). Some studies have shown that magnetization treatment can improve the activity of related enzymes in the plant and increase the metabolism rate of crops (ul Haq et al., 2016). Free water increased in magnetized crop cells, the photochemical activity of chlorophyll increased, the rate of photophosphorylation accelerated, and the net photosynthetic rate increased (Huuskonen et al., 1998).

The relationship between photosynthetic parameters of cotton irrigated with magnetized brackish water was fitted and analyzed (Fig. 5). There was a positive linear relationship between net photosynthetic rate and stomatal conductance (Fig. 5A, $R^{2}=0.496$ ), indicating that the increase of photosynthesis under magnetized brackish water irrigation was caused by the increase of stomatal conductance of leaves (Liu et al., 2009). There was also a positive linear correlation between the transpiration rate and stomatal conductance (Fig. $5 B, R^{2}=0.544$ ). The reason was that magnetization promoted the stomatal opening of cotton leaves, and high stomata led to high transpiration (Yang et al., 2013). The slope of net photosynthetic rate and stomatal conductance (35.11) was greater than that of transpiration rate and stomatal conductance (11.49), which was due to the increase of stomatal conductance, and the rise of transpiration rate was lagging 
behind that of stomatal conductance. Therefore, the slope of the net photosynthetic rate and stomatal conductance was greater than that of transpiration rate and stomatal conductance. The net photosynthetic rate of cotton irrigated with magnetized brackish water was negatively correlated with stomatal limitation value (Fig. 5C, $R^{2}=0.429$ ), which indicated that stomatal limitation was the dominant type of photosynthesis restriction. The results showed that the amount of carbon dioxide entering the leaves provided sufficient raw materials for photosynthetic reaction. Instantaneous water use efficiency was negatively correlated with the stomatal limitation value (Fig. 5D, $R^{2}=0.151$ ), and the correlation coefficients were low. Magnetized brackish water irrigation could improve the water use efficiency of cotton by reducing stomatal limitation and enhancing photosynthesis use efficiency (Zlotopolski, 2017).

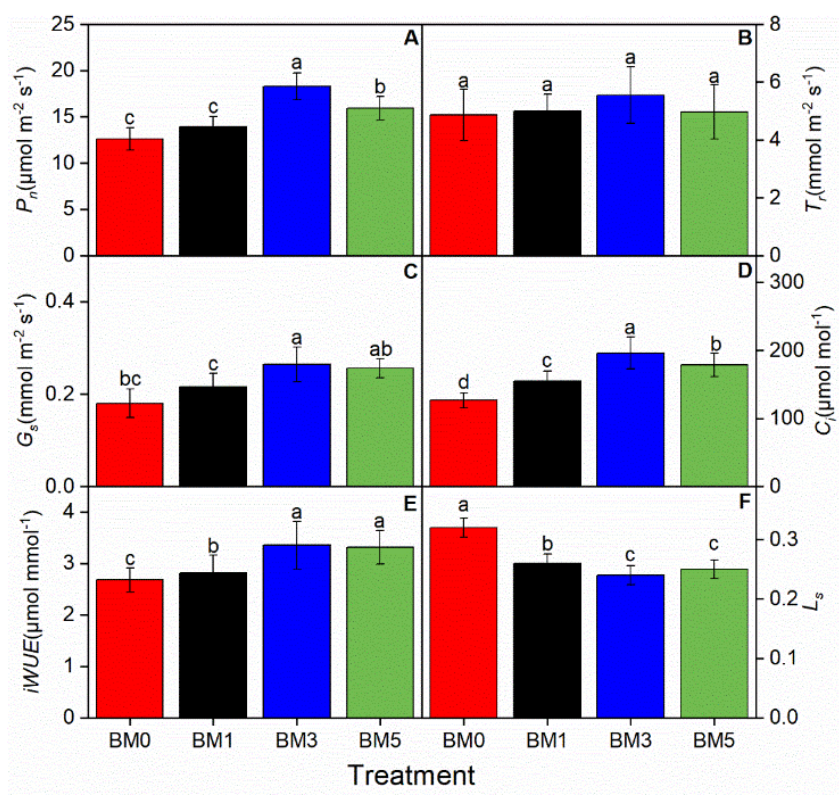

Figure 4. Characteristic photosynthetic parameters of cotton irrigated with magnetized and unmagnetized brackish water. FMO represents unmagnetized brackish water, while BM1, BM3 and BM5 represent brackish water treated with magnetic field intensities of $100 \mathrm{mT}, 300 \mathrm{mT}$ and $500 m T$, respectively. $P_{n}, G_{s}, C_{i}, T_{r}, i W U E$ and $L_{s}$ represent the net photosynthetic rate, stomatal conductance, intercellular $\mathrm{CO}_{2}$ concentration, transpiration rate, instantaneous water use efficiency and stomatal limit, respectively $(n=3)$. The error bars represent standard deviations.

Different letters within a column indicate significant differences among all treatments at $P<0.05$

\section{Effect of magnetized brackish water irrigation on cotton biomass and its distribution}

Biomass is the basis of crop yield (Richards et al., 2019), and magnetized brackish water affects the final yield of crops through the dry matter accumulation process of magnetized water (Ghanati et al., 2015). According to the cotton biomass analysis, there was a significant difference between magnetized and unmagnetized brackish water treated cotton, but there was no significant difference between different magnetization intensities (Table 3). Compared with unmagnetized brackish water, magnetized brackish water irrigated stem, leaf, root dry weight and total dry matter increased by $2.7-18.4 \%$, $1.9-20.0 \%, 52.2-69.3 \%$, and 5.5-20.7\%, respectively, among which the root dry weight increased the most. In terms of stem weight ratio, BM5 reduced by $7.9 \%$ compared with 
BM0, while BM1 and BM3 had no significant difference from BM0. For leaf weight ratio, there was no significantly difference between magnetized and unmagnetized brackish water. For root shoot ratio, BM1, BM3 and BM5 increased by 22.4\%, 54.9\%, and 41.0\%, respectively, compared to $\mathrm{BM} 0$, while the difference between different magnetic field strengths was not significant. The root system is an important organ that is in direct contact with the soil and is responsible for absorbing soil water and nutrients. The health of the root system directly affects crop growth and yield (Hefner et al., 2019). Seedling root weight of cotton irrigated with magnetized water was significantly higher than that of unmagnetized water, which indicated that magnetization could promote root growth and development in cotton seedlings, improve the selective absorption capacity for nutrient ions, and avoid excessive absorption of $\mathrm{Na}^{+}$in cells and the resulting damage, thus reducing the inhibitory effect of salt stress on the growth of cotton seedlings (Liu et al., 2019b). Magnetized brackish water can increase the frequency of mitosis of plant cells, increase RNA content in root tip growth area, accelerate root tissue differentiation, promote cell volume increase in the root elongation area, promote radicle elongation, and enhance absorption of nutrients by roots (Boe and Salunkhe, 1963). Therefore, magnetized brackish water can enhance the absorption of water and nutrients by increasing the dry matter ratio of roots, thus promoting the accumulation of total biomass of cotton as a whole (Liu et al., 2017).
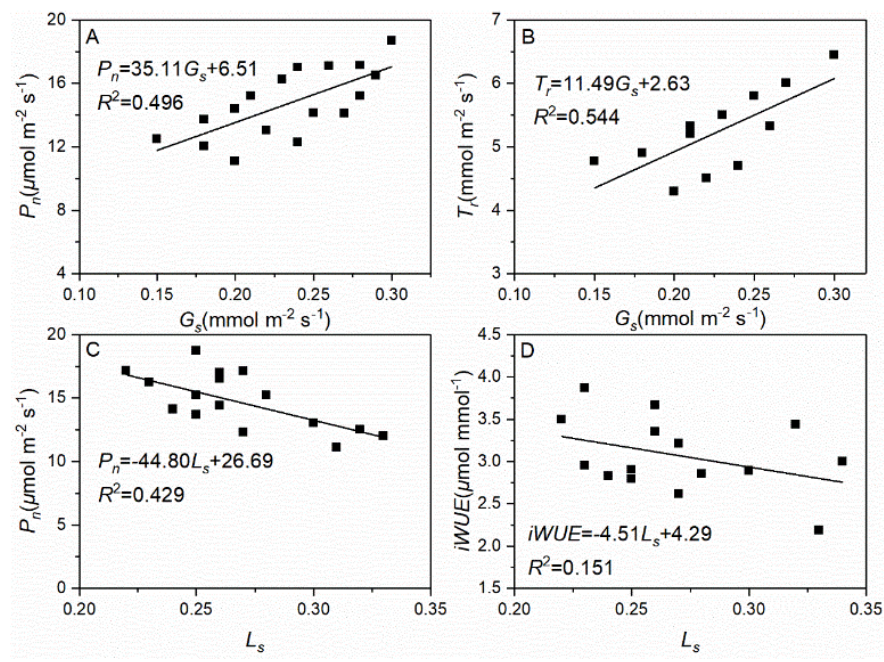

Figure 5. Linear regression between indicators related photosynthesis. $P_{n}, G_{s}, T_{r}, i W U E$ and $L_{s}$ represent the net photosynthetic rate, stomatal conductance, transpiration rate, instantaneous water use efficiency and stomatal limit, respectively $(n=3)$. The error bars represent standard deviations. Different letters within a column indicate significant differences among all treatments at $P<0.05$

Table 3. Biomass and its distribution of cotton irrigated with magnetized and unmagnetized brackish water $(n=3)$

\begin{tabular}{c|c|c|c|c|c|c|c}
\hline Treatment & Stem $(\mathbf{g})$ & Leaf $(\mathbf{g})$ & Root $(\mathbf{g})$ & $\begin{array}{c}\text { Total dry } \\
\text { weight }(\mathbf{g})\end{array}$ & $\begin{array}{c}\text { Stem weight } \\
\text { ratio }(\%)\end{array}$ & $\begin{array}{c}\text { Leaf weight } \\
\text { ratio }(\%)\end{array}$ & $\begin{array}{c}\text { Root shoot } \\
\text { ratio }(\%)\end{array}$ \\
\hline BM0 & $5.01 \pm 0.07 \mathrm{~b}$ & $9.87 \pm 0.19 \mathrm{~b}$ & $1.05 \pm 0.09 \mathrm{~b}$ & $15.94 \pm 0.22 \mathrm{~b}$ & $31.47 \pm 0.85 \mathrm{a}$ & $61.93 \pm 0.35 \mathrm{a}$ & $7.07 \pm 0.58 \mathrm{~b}$ \\
$\mathrm{BM} 1$ & $5.15 \pm 0.43 \mathrm{~b}$ & $10.05 \pm 1.13 \mathrm{~b}$ & $1.60 \pm 0.18 \mathrm{a}$ & $16.81 \pm 1.22 \mathrm{~b}$ & $30.73 \pm 3.25 \mathrm{a}$ & $59.74 \pm 3.39 \mathrm{a}$ & $10.53 \pm 0.56 \mathrm{a}$ \\
$\mathrm{BM} 3$ & $5.93 \pm 0.17 \mathrm{a}$ & $11.62 \pm 0.22 \mathrm{ab}$ & $1.68 \pm 0.13 \mathrm{a}$ & $19.24 \pm 0.25 \mathrm{a}$ & $30.84 \pm 0.51 \mathrm{a}$ & $60.41 \pm 0.36 \mathrm{a}$ & $9.60 \pm 0.92 \mathrm{a}$ \\
$\mathrm{BM} 5$ & $5.56 \pm 0.48 \mathrm{ab}$ & $11.85 \pm 1.27 \mathrm{a}$ & $1.78 \pm 0.12 \mathrm{a}$ & $19.19 \pm 1.68 \mathrm{a}$ & $28.97 \pm 0.62 \mathrm{~b}$ & $61.67 \pm 1.19 \mathrm{a}$ & $10.34 \pm 1.54 \mathrm{a}$ \\
\hline
\end{tabular}

Different letters within a column indicate significant differences among all treatments at $\mathrm{P}<0.05$ 


\section{Conclusions}

The germination potential, germination rate, germination index, and vigor index of magnetized brackish water cotton were all significantly increased, and the increase range of germination potential was greater than that of germination rate, while that of vigor index was greater than that of germination index. The emergence rate of cotton irrigated with magnetized brackish water was 7.5-41.9\%, and full seedling formation of cotton irrigated with $300 \mathrm{mT}$ magnetized brackish water was advanced by $1 \mathrm{~d}$. Under magnetized brackish water irrigation, the seedling vigor indexes such as seedling length, seedling root length, seedling brackish weight, seedling dry weight, and seedling water content were significantly increased $(P<0.05)$. The increase range of seedling root length and seedling brackish weight was larger, while the increase range of seedling water content was slight. Magnetized brackish water with different intensities could improve cotton photosynthesis and water use efficiency, promote cotton morphological development, and increase cotton biomass. Under the magnetic field strength of $300 \mathrm{mT}$, the magnetized brackish water irrigation is most beneficial to the growth of cotton seedlings. In agricultural irrigation, $300 \mathrm{mT}$ magnetic field strength should be used to magnetize brackish water to improve the effectiveness of brackish water resources. The results can provide guidance for the efficient utilization of magnetized brackish water in arid and semiarid areas. However, this study only focused on the magnetization of brackish water quality and its effect on the growth of early cotton seedlings, while the effects of magnetized water with different water quality on the physiological growth characteristics, yield, and quality of cotton at the later growth stage need to be further studied.

Acknowledgements. This study was funded by the National Natural Science Foundation of China (41830754, 51239009 and 41907010), Basic Research Plan of Natural Science of Shaanxi Province (2020JQ-616).

\section{REFERENCES}

[1] Aghamir, F., Bahrami, H. A., Malakouti, M. J., Eshghi, S. (2015): Magnetized water effects on seed germination and seedling growth of corn (Zea mays) under saline conditions. American Journal of Life Sciences 3(2): 184-195.

[2] Al-Ogaidi, A. A. M., Wayayok, A., Rowshon, M. K., Abdullah, A. F. (2017): The influence of magnetized water on soil water dynamics under drip irrigation systems. - Agricultural Water Management 180: 70-77.

[3] Alavi, S. A., Ghehsareh, A. M., Soleymani, A., Panahpour, E., Mozafari, M. (2020): Peppermint (Mentha piperita L.) growth and biochemical properties affected by magnetized saline water. - Ecotoxicology and Environmental Safety 201: 110775.

[4] Alfaidi, M. A., Al-Toukhy, A. A., Al-Zahrani, H. S., Howladar, M. M. (2017): Effect of irrigation by magnetized sea water on guinea grass (Panicum maximum) leaf content of chlorophyll a, b, carotenoids, Pigments, protein \& proline. - Advances in Environmental Biology 11(1): 73-84.

[5] Aliverdi, A., Parsa, M., Hammami, H. (2015): Increased soybean-rhizobium symbiosis by magnetically treated water. - Biological Agriculture \& Horticulture 31(3): 167-176.

[6] Boe, A. A., Salunkhe, D. K. (1963): Effects of magnetic fields on tomato ripening. - Nature 199(4888): 91-92.

[7] Castillo, G., Flores-Enríquez, V., Márquez-Guzmán, J., Núñez-Farfán, J., Oyama, K., Collazo-Ortega, M. (2017): Coping with stressful environments: An experimental study of seed germination and seedling survival of Mexican riverweeds under natural conditions. - 
Aquatic Botany 138: 24-28.

[8] Chen, W. L., Jin, M. G., Ferré, T. P. A., Liu, Y. F., Huang, J. O., Xian, Y. (2020): Soil conditions affect cotton root distribution and cotton yield under mulched drip irrigation. Field Crops Research 249: 107743.

[9] Dziedzic, E., Bieniasz, M., Kowalczyk, B. (2019): Morphological and physiological features of sweet cherry floral organ affecting the potential fruit crop in relation to the rootstock. - Scientia Horticulturae 251: 127-135.

[10] Faulkner, P. C., Hala, D., Rahman, M. S., Petersen, L. H. (2019): Short-term exposure to $12 \%$ brackish water has significant effects on the endocrine physiology of juvenile American alligator (Alligator mississippiensis). - Comparative Biochemistry and Physiology Part A: Molecular \& Integrative Physiology 236: 110531.

[11] Fu, Q. L., Liu, C., Ding, N. F., Lin, Y. C., Guo, B. (2010): Ameliorative effects of inoculation with the plant growth-promoting rhizobacterium Pseudomonas sp. DW1 on growth of eggplant (Solanum melongena L.) seedlings under salt stress. - Agricultural Water Management 97(12): 1994-2000.

[12] Ghanati, F., Mohamadalikhani, S., Soleimani, M., Afzalzadeh, R., Hajnorouzi, A. (2015): Change of growth pattern, metabolism, and quality and quantity of maize plants after irrigation with magnetically treated water. - Electromagnetic Biology and Medicine 34(3): 211-215.

[13] Hadi, S. M. S., Ahmed, M. Z., Hameed, A., Khan, M. A., Gul, B. (2018): Seed germination and seedling growth responses of toothbrush tree (Salvadora persica Linn.) to different interacting abiotic stresses. - Flora 243: 45-52.

[14] Hasan, M. M., Alharby, H. F., Hajar, A. S., Hakeem, K. R. (2017): Leaf gas exchange, $\mathrm{Fv} / \mathrm{Fm}$ ratio, ion content and growth conditions of the two Moringa species under magnetic water treatment. - Pakistan Journal of Botany 49(3): 921-928.

[15] Hefner, M., Labouriau, R., Nørremark, M., Kristensen, H. L. (2019): Controlled traffic farming increased crop yield, root growth, and nitrogen supply at two organic vegetable farms. - Soil and Tillage Research 191: 117-130.

[16] Honarparvar, S., Zhang, X., Chen, T., Na, C., Reible, D. (2019): Modeling technologies for desalination of brackish water-toward a sustainable water supply. - Current Opinion in Chemical Engineering 26: 104-111.

[17] Hozayn, M. M., Salim, M. A., El-Monem, A., Amany, A., El-Mahdy, A. A. (2019): Effect of magnetic brackish-water treatments on morphology, anatomy and yield productivity of wheat (Triticum Aestivum). - Alexandria Science Exchange Journal 40: 604-617.

[18] Huang, M. Y., Zhang, Z. Y., Zhu, C. L., Zhai, Y. M., Lu, P. R. (2019): Effect of biochar on sweet corn and soil salinity under conjunctive irrigation with brackish water in coastal saline soil. - Scientia Horticulturae 250: 405-413.

[19] Huuskonen, H., Lindbohm, M. L., Juutilainen, J. (1998): Teratogenic and reproductive effects of low-frequency magnetic fields. - Mutation Research/Reviews in Mutation Research 410(2): 167-183.

[20] Kulmala, L., Pumpanen, J., Kolari, P., Dengel, S., Berninger, F., Köster, K., Matkala, L., Vanhatalo, A., Vesala, T., Bäck, J. (2019): Inter- and intra-annual dynamics of photosynthesis differ between forest floor vegetation and tree canopy in a subarctic Scots pine stand. - Agricultural and Forest Meteorology 271: 1-11.

[21] Li, M., Du, Y. J., Zhang, F. C., Bai, Y. G., Fan, J. Q., Zhang, J. H., Chen, S. M. (2019): Simulation of cotton growth and soil water content under film-mulched drip irrigation using modified CSM-CROPGRO-cotton model. - Agricultural Water Management 218: 124-138.

[22] Liang, S. M., Ren, C., Wang, P. J., Wang, X. T., Li, Y. S., Xu, F. H., Wang, Y., Dai, Y. Q., Zhang, L., Li, X. P., Zhan, K., Yang, Q. F., Sui, Q. J. (2018): Improvements of emergence and tuber yield of potato in a seasonal spring arid region using plastic film mulching only on the ridge. - Field Crops Research 223: 57-65.

[23] Liang, J. P., He, Z. J., Shi, W. J. (2020): Cotton/mung bean intercropping improves crop 
productivity, water use efficiency, nitrogen uptake, and economic benefits in the arid area of Northwest China. - Agricultural Water Management 240: 106277.

[24] Liu, F. L., Andersen, M. N., Jensen, C. R. (2009): Capability of the 'Ball-Berry'model for predicting stomatal conductance and water use efficiency of potato leaves under different irrigation regimes. - Scientia Horticulturae 122(3): 346-354.

[25] Liu, X. M., Ma, F. Y., Zhu, H., Ma, X. S., Guo, J. Y., Wan, X., Wang, L., Wang, H. T., Wang, Y. P. (2017): Effects of magnetized water treatment on growth characteristics and ion absorption, transportation, and distribution in Populus $\times$ euramericana 'Neva' under $\mathrm{NaCl}$ stress. - Canadian Journal of Forest Research 47(6): 828-838.

[26] Liu, X. M., Wang, L., Cui, H. R., Zhu, H., Bi, S. S., Zhang, Z. H., Meng, S. Y., Song, C. D., Wang, H. T., Ma, F. Y. (2019a): Effects of magnetic treatment on the ascorbateglutathione cycle and endogenous hormone levels in Populus $\times$ euramericana 'Neva' under cadmium stress. - Canadian Journal of Forest Research 49(9): 1147-1158.

[27] Liu, X. M., Zhu, H., Meng, S. Y., Bi, S. S., Zhang, Y., Wang, H. T., Song, C. D., Ma, F. Y. (2019b): The effects of magnetic treatment of irrigation water on seedling growth, photosynthetic capacity and nutrient contents of Populus $\times$ euramericana 'Neva' under $\mathrm{NaCl}$ stress. - Acta Physiol Plant 41(11): 1-13.

[28] Liu, X. M., Wang, L., Wei, Y., Zhang, Z. H., Zhu, H., Kong, L. G., Meng, S. Y., Song, C. D., Wang, H. T., Ma, F. Y. (2020): Irrigation with magnetically treated saline water influences the growth and photosynthetic capability of Vitis vinifera L. seedlings. - Scientia Horticulturae 262: 109056.

[29] Luo, Y., Liang, J., Zeng, G. M., Li, X. D., Chen, M., Jiang, L. B., Xing, W. L., Tang, N., Fang, Y. L., Chen, X. W. (2019): Evaluation of tetracycline phytotoxicity by seed germination stage and radicle elongation stage tests: A comparison of two typical methods for analysis. - Environmental Pollution 251: 257-263.

[30] Massah, J., Dousti, A., Khazaei, J., Vaezzadeh, M. (2019): Effects of water magnetic treatment on seed germination and seedling growth of wheat. - Journal of Plant Nutrition 42(11-12): 1283-1289.

[31] Mollahosseini, A., Abdelrasoul, A. (2019): Recent advances in thin film composites membranes for brackish groundwater treatment with critical focus on Saskatchewan water sources. - Journal of Environmental Sciences 81: 181-194.

[32] Mosse, K. P., Verheyen, T. V., Cruickshank, A. J., Patti, A. F., Cavagnaro, T. R. (2013): Soluble organic components of winery wastewater and implications for reuse.Agricultural water management 120: 5-10.

[33] Moussa, H. R. (2011): The impact of magnetic water application for improving common bean (Phaseolus vulgaris L.) production. - New York Science Journal 4(6): 15-20.

[34] Murshed, S. B., Kaluarachchi, J. J. (2018): Scarcity of fresh water resources in the Ganges Delta of Bangladesh. - Water Security 4: 8-18.

[35] Qiu, N. W., Tan, Y. H., Shen, X., Han, R., Lin, Y., Ma, Z. Q. (2011): Biological effects of magnetized water on seed germination, seedling growth and physiological characteristics of wheat. - Plant Physiology Communications 47(8): 803-810.

[36] Ramírez-Pérez, L. J., Morales-Díaz, A. B., Benavides-Mendoza, A., de-Alba-Romenus, K., González-Morales, S., Juarez-Maldonado, A. (2018): Dynamic modeling of cucumber crop growth and uptake of N, P and K under greenhouse conditions. - Scientia Horticulturae 234: 250-260.

[37] Richards, R. A., Cavanagh, C. R., Riffkin, P. (2019): Selection for erect canopy architecture can increase yield and biomass of spring wheat. - Field Crops Research 244: 107649.

[38] Sappington, E. N., Rifai, H. S. (2018): Low-frequency electromagnetic treatment of oilfield produced water for reuse in agriculture: effect on water quality, germination, and plant growth. - Environmental Science and Pollution Research 25: 34380-34391.

[39] Sayed, H. E., Sayed, A. E. (2014): Impact of magnetic water irrigation for improve the growth, chemical composition and yield production of broad bean (Vicia faba L.) plant. Journal of Experimental Agriculture International 4: 476-496. 
[40] Shrestha, N. K., Du, X., Wang, J. (2017): Assessing climate change impacts on fresh water resources of the Athabasca River Basin, Canada. - Science of the Total Environment 601: 425-440.

[41] Surendran, U., Sandeep, O., Joseph, E. J. (2016): The impacts of magnetic treatment of irrigation water on plant, water and soil characteristics. - Agricultural Water Management 178: 21-29.

[42] Tan, S., Wang, Q. J., Xu, D., Zhang, J. H., Shan, Y. Y. (2017): Evaluating effects of four controlling methods in bare strips on soil temperature, water, and salt accumulation under film-mulched drip irrigation. - Field Crops Research 214: 350-358.

[43] Tian, F. Q., Yang, P. J., Hu, H. C., Liu, H. (2017): Energy balance and canopy conductance for a cotton field under film mulched drip irrigation in an arid region of northwestern China. - Agricultural Water Management 179: 110-121.

[44] ul Haq, Z., Iqbal, M., Jamil, Y., Anwar, H., Younis, A., Arif, M., Fareed, M. Z., Hussain, F. (2016): Magnetically treated water irrigation effect on turnip seed germination, seedling growth and enzymatic activities. - Information Processing in Agriculture 3: 99-106.

[45] Velmala, S. M., Vuorinen, I., Uimari, A., Piri, T., Pennanen, T. (2018): Ectomycorrhizal fungi increase the vitality of Norway spruce seedlings under the pressure of Heterobasidion root rot in vitro but may increase susceptibility to foliar necrotrophs. - Fungal biology 122(2-3): 101-109.

[46] Wang, P. C., Mo, B. T., Long, Z. F., Fan, S. Q., Wang, H. H., Wang, L. B. (2016): Factors affecting seed germination and emergence of Sophora davidii. - Industrial Crops and Products 87: 261-265.

[47] Wang, X. X., Xu, Z. S., Gou, X. J. (2020): Allocation of fresh water recourses in China with nested probabilistic-numerical linguistic information in multi-objective optimization. - Knowledge-Based Systems 188: 105014.

[48] Yang, Z. S., Quna, Q. M., Wu, T. D. (2013): Difference studies for the stomatal conductance and the leaf Chlorophyll concentration in different positions of Lilium regale leaves. - IERI Procedia 5: 284-290.

[49] Yang, P. J., Hu, H. C., Tian, F. Q., Zhang, Z., Dai, C. (2016): Crop coefficient for cotton under plastic mulch and drip irrigation based on eddy covariance observation in an arid area of northwestern China. - Agricultural Water Management 171: 21-30.

[50] Yue, S. D., Zhou, Y., Zhang, Y., Xu, S. C., Gu, R. T., Xu, S., Zhang, X. M., Zhao, P. (2019): Effects of salinity and temperature on seed germination and seedling establishment in the endangered seagrass Zostera japonica Asch. \& Graebn. in northern China. - Marine pollution bulletin 146: 848-856.

[51] Yusuf, K. O., Ogunlela, A. O. (2015): Impact of magnetic treatment of irrigation water on the growth and yield of tomato. - Notulae Scientia Biologicae 7: 345-348.

[52] Zhong, W. W., Ji, C., Li, H. Y., Hou, J. W., Chen, V. (2018): Fouling mitigation in submerged VMD for the treatment of brackish groundwater concentrates with transverse vibration and crystallizer. - Desalination 426: 32-41.

[53] Zhou, B., Zhou, H. X., Puig-Bargués, J., Li, Y. K. (2019): Using an anti-clogging relative index (CRI) to assess emitters rapidly for drip irrigation systems with multiple low-quality water sources. - Agricultural Water Management 221: 270-278.

[54] Zlotopolski, V. (2017): Magnetic treatment reduces water usage in irrigation without negatively impacting yield, photosynthesis and nutrient uptake in lettuce. - International Journal of Applied Agricultural Sciences 3(5): 117-122. 